\title{
CONTEÚDOS DE INTERPRETAR A LEITURA COMO PASSAPORTE PARA A INTERAÇÃO COM O MUNDO ${ }^{4}$
}

\author{
Ilana da Silva Rebello Viegas (UFF) \\ ilanarebello@uol.com.br
}

(...) ou se educa para a emancipação (conscientização, politização) ou se educa para a submissão (enquadramento, adaptação). (...) (Silva, 2005a, p. 82)

\section{Considerações iniciais}

Os alunos, de modo geral, têm dificuldades para entender e interpretar o que leem, independentemente do grau de escolarização. Diante dessa realidade, como formar leitores? Se a "educação é transformação do homem e do mundo" (SILVA, 2005b, p. 77), como fazer com que o aluno perceba as sutilezas em um texto? Como levá-lo a ultrapassar a compreensão ("sentido de língua"5) e chegar a interpretação ("sentido de discurso")? Existem conteúdos de interpretar? Como tornar o ensino de leitura/compreensão/interpretação em produção de sentidos? Esse é o problema sobre o qual nos debruçamos na tentativa de encontrar possíveis soluções.

\footnotetext{
${ }^{4}$ Este trabalho é um resumo expandido da minha tese de doutorado defendida em outubro de 2009, na UFF.

${ }^{5}$ Para Charaudeau $(1995,1999$, p. 29), "sentido de língua" trabalha apenas com um signo linguístico capaz de associar o significante a um significado pleno nas suas relações sintagmáticas e paradigmáticas. Já no "sentido de discurso", o signo remete a algum significado, mas este não pode ser visto a partir de um valor absoluto e autônomo, mas apenas como portador de um sentido potencial que precisa ser articulado com outros signos e com a prática social.
} 
Estamos de acordo com Silva (2005b, p. 97) quando afirma que "(...) as crianças nunca chegam à escola num estado de ignorância, mas podem chegar analfabetas. Elas talvez não saiam analfabetas, mas podem sair ignorantes...".

Diante dessa realidade, a nossa proposta é que o exercício de leitura/compreensão/interpretação seja significativo, a fim de que os educandos não deixem a escola analfabetos e, muito menos, ignorantes.

Esperamos, assim, contribuir para a ampliação do número de leitores nas escolas, já que "o compromisso primeiro do professor de língua materna é auxiliar o aluno a tornar-se um leitor autônomo e um produtor competente de textos." (FIORIN, 1996, p. 9)

\section{Texto: lugar de produção de sentidos}

Leitura, texto e sentido fazem parte do processo de interpretação. Se não existe texto, seja ele verbal ou não verbal, não há leitura e muito menos produção de sentidos.

A primeira dificuldade que o professor enfrenta ao tentar trabalhar com os alunos estratégias de leitura que os levem a uma interpretação crítica é despertar neles o gosto pela leitura. A primeira barreira parece ser o próprio texto. Porém, "formar leitores, desenvolver competências em leitura e escrita é uma tarefa que a escola tem que priorizar e não pode sequer protelar." (ANTUNES, 2009, p. 201).

Diante dessa tarefa, o que fazer quando os alunos não manifestam interesse em ler? "Os meus alunos não gostam de ler e escrever" é, sem dúvida, a reclamação mais comum ouvida entre professores. Por que essa realidade? Por que a leitura ocupa um lugar cada vez menor no cotidiano das pessoas?

Ninguém gosta de fazer algo que acredita ser difícil demais, nem aquilo de que não consegue extrair sentido. É dessa forma que, geralmente, a tarefa de ler e escrever é vista e vivida em sala de aula: difícil demais, porque não faz sentido.

Segundo Antunes (2009, p. 201),

Não se nasce com o gosto pela leitura, do mesmo modo que não se nasce com o gosto por coisa nenhuma. $\mathrm{O}$ ato de ler não é, pois, uma habilidade inata. (...) o gosto por ler literatura é aprendido por um estado de sedução, de fascí- 


\section{FACULDADE DE FORMAÇÃO DE PROFESSORES}

nio, de encantamento. Um estado que precisa ser estimulado, exercitado e vivido.

O ato de ler, como afirma Silva (2005b, p. 96), "sempre envolve apreensão, apropriação e transformação de significados, a partir de um documento escrito. Leitura sem compreensão e sem recriação do significado é pseudoleitura, (...)."

E, o autor ainda expõe algumas dúvidas sobre o trabalho que é desenvolvido com o texto nas escolas:

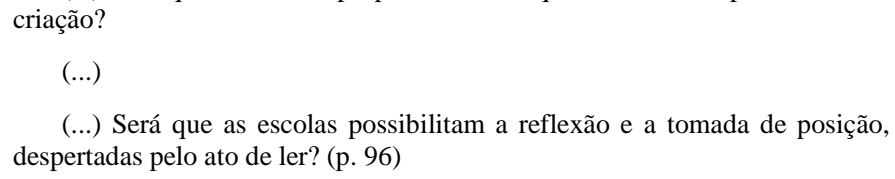
criação?

(...)

(...) Será que as escolas possibilitam a reflexão e a tomada de posição, despertadas pelo ato de ler? (p. 96)

(...) Será que as escolas propõem leituras que levam à compreensão e re-

Dessa forma, conversando com alunos de níveis de ensino diferentes, percebemos que os mesmos não gostam de ler, porque sabem que, ao final da leitura, terão que responder uma lista de questões que não fazem sentido para eles. Em alguns casos, realmente, as perguntas não fazem sentido ${ }^{6}$; porém, na maioria das vezes, falta algum conhecimento por parte dos educandos para que possam chegar aos implícitos do texto.

No discurso popular, circula a seguinte frase: "Só se aprende a fazer, fazendo". Assim, de nada adianta estudarmos teorias sobre textos, se não as praticarmos. Em sala de aula, como desenvolver nos alunos competências de leitura e escrita, se eles não têm o mínimo interesse em ler? Como fazer com que eles sintam prazer em ler e entender o que leem? Que o texto exige do leitor? Que significa ler?

Magda Soares apud Dell'Isola (2001, p. 8) afirma que

(...) a leitura não é uma atividade de mera decodificação, em que o leitor aprende, compreende e interpreta a "mensagem" do autor, mas é processo constitutivo do texto: é na interação autor/leitor que o texto é construído, é produzido. Ou seja: o texto não preexiste à sua leitura, pois esta é construção ativa de um leitor que, de certa forma, "reescreve o texto", determinado por seu repertório de experiências individuais, sociais e culturais.

\footnotetext{
${ }^{6}$ Remeto o leitor a dois trabalhos que fazem uma análise crítica das perguntas de exercícios de interpretação: Marcuschi $(2001,1996)$ e Feres (2003).
} 
Sendo assim, ler um texto não é decodificar a mensagem. Para Marcuschi ${ }^{7}$ (2008, p. 239), só se pode falar em leitura quando há compreensão.

Ler e compreender são equivalentes. (...) ler equivale a ler compreensivamente. (...)

A compreensão de texto é um processo cognitivo. (...)

(...) compreender é partir dos conhecimentos (informações) trazidos pelo texto e dos conhecimentos pessoais (chamados de conhecimentos enciclopédicos) para produzir (inferir) um sentido como produto de nossa leitura. (...)

Os conhecimentos prévios exercem uma influência muito grande ao compreendermos um texto. (...)

Compreender um texto não equivale a decodificar mensagens.(...)

Segundo Dell'Isola (2001, p. 107), há processos decisivos que compõem o mecanismo da leitura. Num primeiro momento, o leitor decodifica o texto, para posteriormente compreender a informação explícita. Em seguida, seleciona o que considera mais significativo, de acordo com a sua visão de mundo, direcionando a sua leitura a uma determinada compreensão específica.

O segundo momento consiste em ler as "entrelinhas" e integrar os dados do texto à própria experiência ou conhecimento do mundo. O leitor infere de acordo com seu conhecimento de mundo, que está enraizado em uma sociedade e em uma cultura. É nesse momento que ele consegue sair do nível da compreensão para ir mais além na leitura, ou seja, interpretar o que lê.

Após as inferências, o leitor é levado a se posicionar emocional e afetivamente diante do texto e a avaliar os fatos que lhe forem apresentados. E, por último, aquilo que for significativo para o leitor fica retido na memória, podendo ser ativado em outros momentos, para o entendimento de situações comunicativas diversas.

É importante lembrar que, o aluno precisa perceber que "um texto permite muitas leituras, mas não infinitas. (...) compreender é produzir modelos cognitivos compatíveis preservando o valor-verdade". (MARCUSCHI, 2008, p. 257) (Grifo nosso).

${ }^{7} \mathrm{O}$ autor não faz distinção entre compreender e interpretar. 


\section{FACULDADE DE FORMAÇÃO DE PROFESSORES}

A leitura, sendo compromisso de todas as áreas (Cf. NEVES et alli (Orgs.), 2007) deve permitir que o sujeito interpretante não aprenda a repetir palavras, mas a dizer a sua palavra. Como afirma Citelli (1994, p. 50) apud Seffner (2007, p. 113),

É necessário ter claro que desenvolver uma competência para a leitura (da palavra) implica contribuir no sentido da formação de um cidadão mais pleno, que possa, criticamente, se assenhorar de um mecanismo tradicionalmente utilizado pela classe dominante. Tomar posse da palavra não para refazer o circuito da discriminação, mas para forçar espaços de libertação.

\section{Nossa proposta: um trabalho de interpretação em sequências didá- ticas}

Sugerimos, para fins didáticos, o trabalho com sequências didáticas. Dolz \& Schneuwly (2004, p. 97) definem "uma "sequência didática" (como) um conjunto de atividades escolares organizadas, de maneira sistemática, em torno de um gênero textual oral ou escrito.

O trabalho com textos organizados em sequências didáticas tem por objetivo ajudar o aluno a dominar melhor um gênero de texto, permitindo-lhe, assim, ultrapassar o sentido de língua. Se o aluno for capaz de interpretar o que lê, terá, sem dúvida, mais facilidade para se expressar e produzir diferentes textos de acordo com a situação de comunicação.

Normalmente, nas aulas de língua portuguesa, as atividades gramaticais ocupam a maior parte do tempo. Um dos motivos está na ênfase que os manuais didáticos dão às regras gramaticais, como se as atividades de leitura, interpretação e produção textual não exigissem estudo e "conteúdos" a serem desenvolvidos. Como observam Dolz \& Schneuwly (2004, p. 50),

(...) Tudo se passa como se a capacidade de produzir textos fosse um saber que a escola deve encorajar, para facilitar a aprendizagem, mas que nasce e se desenvolve fundamentalmente de maneira espontânea, sem que pudéssemos ensiná-la sistematicamente.

Carneiro (2002, p. 211), em sua tese de doutorado sobre interpretação de texto, faz a seguinte observação

(...) [nas] aulas de conteúdo gramatical ou literário, as anotações (no diário) do que foi ensinado são bem claras, com informações precisas sobre os itens abordados; mas, quando se trata de interpretação de texto, os dados são bem poucos, no máximo o título e o autor do texto analisado. Mas, o que foi ensinado na atividade? As perguntas formuladas supõem algum conhecimento adquirido nas séries anteriores? 
E, Carneiro (2002, p. 211) conclui que

$\mathrm{Na}$ verdade, falta aos professores um programa, que só poderá ser construído a partir de uma sistematização dos conhecimentos textuais. Como tal sistematização ainda não foi realizada de forma adequada, continuamos nós, os professores, a construir a tarefa de forma intuitiva.

Dessa forma, pesquisas realizadas com professores e atividades desenvolvidas com alunos mostram que é necessário o estabelecimento de objetivos a serem cumpridos no ensino e aprendizagem da interpretação textual. É preciso que o professor tenha consciência do que seja texto e de seu funcionamento como estrutura produtora de sentido, pois ensinar a ler e a interpretar é perceber os conteúdos e os conhecimentos que se tornam dizíveis por meio dos textos; reconhecer os elementos das estruturas comunicativas e semióticas partilhadas pelos textos reconhecidos como pertencentes ao gênero e, por fim, identificar as configurações específicas de unidades de linguagem, traços, principalmente, da posição enunciativa do enunciador e dos conjuntos particulares de sequências textuais e de tipos discursivos que formam sua estrutura. (Cf. DOLZ \& SCHNEUWLY, 2004, p. 75).

Cada gênero pode ser abordado em diferentes níveis de complexidade. A retomada de objetivos já trabalhados, após um certo espaço de tempo e, numa nova perspectiva, é indispensável para que a aprendizagem seja assegurada.

Dolz \& Schneuwly (2004) propõem um trabalho com sequências didáticas, em torno de um gênero textual. Aproveitamos a sugestão dos autores, porém organizamos as nossas sequências a partir dos modos de organização do discurso.

Assim, para fins didáticos, propomos um trabalho com sequências didáticas a partir dos modos de organização do discurso apresentados por Charaudeau $(1992,2008)$, com uma pequena alteração. Charaudeau cita como modo de organização o argumentativo. Preferimos denominálo de dissertativo, a fim de separar os textos, de acordo com a função, em dois blocos: expositivo e argumentativo.

Optamos também pelas tipos de textos propostos por Carneiro (2005). O autor, tomando como base a função textual cita nove tipos, a saber - normativos (regulamentar), fáticos (contatar), expressivos (automanifestar-se), apelativos (convencer), didáticos (ensinar), instrucionais (instruir), informativos (informar), preditivos (prever) e literários (função estética). 
O esquema seguinte resume nossa proposta:

\begin{tabular}{|c|l|}
\hline $\begin{array}{c}\text { Modos de organi- } \\
\text { zação do discurso: }\end{array}$ & $\begin{array}{l}\text { Enunciativo, descritivo, narrativo e dissertativo (expositi- } \\
\text { vo e argumentativo). }\end{array}$ \\
\hline Tipos de textos: & $\begin{array}{l}\text { Normativos, fáticos, expressivos, apelativos, didáticos, } \\
\text { instrucionais, informativos, preditivos e literários. }\end{array}$ \\
\hline Gêneros textuais: & $\begin{array}{l}\text { (Cada tipo tem seus gêneros) } \\
\text { Oração, requerimento, cartaz publicitário etc. }\end{array}$ \\
\hline
\end{tabular}

Tabela 1 - Nossa proposta - Fonte: Charaudeau (1992, 2008); Carneiro (2005)

$\mathrm{O}$ trabalho proposto é dividido em quatro sequências didáticas, de acordo com um modo de organização do discurso. Em cada sequência, constam diferentes tipos de textos, tendo em vista que são explorados diversos gêneros textuais. As sequências são divididas em módulos, nos quais serão explorados os gêneros. $\mathrm{O}$ modo enunciativo não encabeça uma sequência, já que perpassa todos os outros. Esse modo tem por objetivo "organizar as categorias da língua, ordenando-as de forma a que deem conta da posição que o sujeito falante ocupa em relação ao interlocutor, em relação ao que ele diz e em relação ao que o outro diz." (Cf. CHARAUDEAU, 2008, p. 82).

Diante disso, no trabalho de língua portuguesa, um mesmo gênero textual permite que o professor explore, com seus alunos, diferentes categorias de língua e, consequentemente, diferentes modos de organização do discurso.

Em termos didáticos, para cada modo de organização do discurso, citamos alguns conteúdos de interpretar. O modo enunciativo, mesmo sem encabeçar uma sequência didática, tem conteúdos de interpretar que podem ser explorados nos outros modos.

Apresentamos, a seguir, um quadro com algumas sugestões dos "conteúdos de interpretar" para cada modo de organização do discurso.

\begin{tabular}{|l|l|}
\hline \multicolumn{2}{|c|}{ Conteúdos de interpretar para cada modo de organização do discurso } \\
\hline Enunciativo & $\begin{array}{l}\text { O emissor, o receptor e a mensagem na situação de comunicação; } \\
\text { A comunicação oral e escrita; } \\
\text { Fatores que interferem na comunicação; } \\
\text { Atitudes enunciativas que o sujeito falante constrói em função }\end{array}$ \\
$\bullet \quad$ dos elementos de identificação, \\
$\bullet \quad$ da situação de comunicação e \\
$\qquad \quad$ da imagem que o falante quer transmitir de si mesmo ao \\
\\
$\begin{array}{l}\text { Utilização do jogo da modalização e dos atos locutivos. } \\
\text { Diferentes efeitos de saber, de realidade/ficção, de confidência e de } \\
\text { gênero. }\end{array}$ \\
\hline
\end{tabular}




\begin{tabular}{|c|c|}
\hline & $(\ldots)$ \\
\hline Narrativo & $\begin{array}{l}\text { Relação entre sentido e contexto; } \\
\text { Figuras de linguagem; } \\
\text { Verificação de como se realiza a passagem de tempo no texto; } \\
\text { As marcas explícitas de sucessão cronológica; } \\
\text { As marcas implícitas da sucessão psicológica; } \\
\text { Observação dos diferentes valores dos tempos verbais do passado; } \\
\text { Efeitos de distância, de proximidade e de atualidade; } \\
\text { As formas de designar os personagens na narrativa; } \\
\text { Atos de fala; } \\
\text { Figurativização/Tematização. } \\
\text { (...) }\end{array}$ \\
\hline Descritivo & $\begin{array}{l}\text { Ato de Nomear (identidades nominais); } \\
\text { Ato de Qualificar (identidades descritivas: atributos); } \\
\text { Descrição objetiva e descrição subjetiva; } \\
\text { Apreensão do tema-núcleo; } \\
\text { Meios de identificar/nomear, instruir, listar, localizar (no tempo e } \\
\text { no espaço) ou caracterizar o tema núcleo; } \\
\text { O observador. } \\
\text { (...) }\end{array}$ \\
\hline $\begin{array}{l}\text { Dissertativo } \\
\text { expositivo }\end{array}$ & $\begin{array}{l}\text { Expressão de fatos conectados por elementos lógicos; } \\
\text { Estrutura do texto expositivo; } \\
\text { Agentes animados e inanimados; } \\
\text { Relações de condição e de hipótese; } \\
\text { Conectores; } \\
\text { A expressão dos fatos de forma impessoal, passiva e pronominal; } \\
\text { Consideração do destinatário: a seleção linguística; } \\
\text { Perguntas retóricas; } \\
\text { Processos de condensação discursiva; } \\
\text { Regras de apresentação. } \\
\text { (...) }\end{array}$ \\
\hline $\begin{array}{l}\text { Dissertativo } \\
\text { argumentativo }\end{array}$ & $\begin{array}{l}\text { Os métodos argumentativos da sedução; } \\
\text { Intimidação; } \\
\text { Gratificação e competição; } \\
\text { A figura do argumentador; } \\
\text { O tema e a tese; } \\
\text { Tipos de raciocínio. } \\
\text { (...) }\end{array}$ \\
\hline
\end{tabular}

Tabela 2 - Conteúdos de interpretar para cada modo de organização do discurso

A lista de conteúdos proposta é aberta. Em termos de um trabalho didático, listamos apenas alguns. Cabe ao professor, selecionar os conteúdos pertinentes aos gêneros com os quais deseja trabalhar, sempre levando em consideração que o trabalho com tais conteúdos deve ser sistemático. $\mathrm{O}$ aluno precisa saber interpretar um número maior possível de gêneros textuais. 


\section{FACULDADE DE FORMAÇÃO DE PROFESSORES}

Em 2009, fizemos uma testagem da nossa proposta de trabalho em sequências didáticas. Aplicamos duas atividades avaliativas, sendo que a primeira foi realizada sem explicação prévia a respeito do gênero textual em questão - fábula. Ao final das questões de compreensão e interpretação, foi solicitado que o aluno produzisse uma fábula. Na primeira avaliação, dos 35 alunos, apenas 14 (40\%) produzirem um texto de acordo com a proposta. Já na segunda avaliação, todos os alunos produziram o texto adequado à proposta.

Assim, os resultados dessa testagem revelam que se da mesma forma que existem conteúdos gramaticais para serem trabalhados sistematicamente do $1^{\circ}$ Ano de Escolaridade do Ensino Fundamental ao $3^{\circ}$ Ano de Escolaridade do Ensino Médio, houvesse um trabalho sistemático com conteúdos de interpretar, teríamos uma população com um nível de leitura e escrita muito melhor.

É importante também destacar que, às vezes, a dificuldade de interpretar o que lê se deve ao fato de o aluno vivenciar conteúdos estanques em interpretação. Ou seja, ensina-se hoje as características de uma narração e esse conteúdo não é retomado. Se os conteúdos forem trabalhados em forma de "elos", ou seja, sempre sendo retomados, fixados e comparados com os novos conteúdos, permanecerão por muito mais tempo na memória dos alunos.

\section{Considerações finais}

Em Educação, é comum ouvirmos reclamações de professores sobre os baixos salários e as péssimas condições de trabalho e até mesmo sobre a falta de interesse dos alunos. E o mais interessante é que, apesar de tanta desilusão, cansaço e medo, o professor não desiste nunca e, prova disso, são as inúmeras pesquisas que têm sido desenvolvidas na área. O professor procura sempre desenvolver o seu trabalho da melhor maneira possível, mesmo que, às vezes, esse "possível" nem sempre traga bons resultados.

O professor sabe que "ensinar é um exercício de imortalidade" (ALVES, p. 2004) e que é uma "peça chave" na formação de um estudante, pois "(...) ou se educa para a emancipação (conscientização, politização) ou se educa para a submissão (enquadramento, adaptação)." (SILVA, 2005a, p. 82). E o que a escola tem feito? Será que tem deixado 
acesa a chama da busca pelo conhecimento? “(...) Mudar é difícil, mas é possível" (FREIRE, 1996, p. 88).

Reclamar que o ensino não caminha bem e continuar fazendo o mesmo só aumenta o número de pessoas alienadas na sociedade, pois nesse caso, o professor estará "educando" para o enquadramento do indivíduo na comunidade em que ele vive, sem levá-lo a tomar consciência de seu papel enquanto sujeito, fazedor de sua história no mundo. É preciso levar o aluno a "transformar a realidade, para nela intervir, recriandoa, (...)" (FREIRE, 1996, p. 76).

Imagine se um médico continua insistindo em receitar o mesmo remédio que não está dando resultado para um determinado paciente? Se o paciente não morrer, ao menos não ficará curado. $\mathrm{O}$ mesmo podemos dizer em relação ao processo de ensino-aprendizagem na escola. Se quisermos resultados positivos, precisamos acreditar e procurar novas estratégias que despertem no aluno a busca pelo conhecimento.

Assim, este trabalho partiu de um problema vivenciado nas salas de aulas por muitos professores - os alunos, de modo geral, têm dificuldades para entender e interpretar o que leem, independentemente do grau de escolarização. Tal fato não é constatado apenas nas salas de aula, mas até mesmo, pessoas que já terminaram o Ensino Médio não apresentam um domínio de leitura e escrita adequado para o nível de escolaridade concluído.

Em 2006, 2007 e 2008, aplicamos algumas atividades de compreensão e interpretação para estudantes do Ensino Fundamental e Médio. Obtivemos 695 respostas do grupo de interpretação, porém, 405 foram respostas não-adequadas à proposta de atividade. Tal dado mostra que é necessário um trabalho consciente com o texto nas escolas.

Os resultados do INAF/Brasil (Indicador Nacional de Alfabetismo Funcional) mostram que os governantes do Brasil têm-se esforçado em universalizar o acesso e estimular o maior tempo possível de permanência dos estudantes na escola. Tais esforços, sem dúvida, têm produzido resultados na melhoria das capacidades de alfabetismo da população brasileira. Porém, além de viabilizar o acesso, é preciso investir na qualidade, a fim de que a escolarização garanta, de fato, as aprendizagens necessárias para que os cidadãos se insiram de forma autônoma e responsável na sociedade moderna. De que adianta um diploma sem o conhecimento adquirido?! 


\section{FACULDADE DE FormaÇÃo de PROFESSORES}

O professor reclama, mas nem sempre dá o "remédio" certo. Se o aluno não sabe interpretar o que lê, precisamos ensiná-lo. Mas de que forma?

Pesquisa realizada com educadores mostra que "conteúdos de interpretar" são desconhecidos por muitos. E, fazer do texto um pretexto para o ensino da gramática não é um bom caminho. Dos professores entrevistados (15), somente seis citaram algum conteúdo voltado para a atividade de interpretação.

Assim, "ensinar a ler não implica apenas alfabetizar ou propiciar o acesso aos livros" (MARTINS, 1994, p. 34), mas "conduzir" o leitor aos implícitos do texto. Como diz Antunes (2009, p. 206), "se desde o início, for dada aos alunos a oportunidade da leitura plena (do livro e do mundo) - aquela que desvenda, que revela, que lhes possibilita uma visão crítica do mundo e de si mesmos (...), uma nova ordem de cidadãos poderá surgir e, dela, uma nova configuração de sociedade."

O problema já é visível e os profissionais da Educação devem fazer por onde e procurar estratégias de ensino que ponham fim no problema apresentado. Parece otimismo exacerbado, mas se não for possível erradicar o problema, pelo menos, é possível amenizar, a fim de que a educação brasileira não caminhe a passos largos para a total alienação dos estudantes.

Metaforicamente, a leitura pode ser entendida como um passaporte para a interação com o mundo. No termo passaporte subentende-se "permissão legítima", o que nos leva a ver a leitura - não apenas da palavra, mas do mundo - como um meio ou, talvez, o meio de interação legítima do leitor com o mundo. A falta de leitura pode imobilizar o homem no sentido de que ele terá mais dificuldade para entender o mundo e tomar a sua palavra.

Parafraseando o poeta Thiago Melo, o caminho não é novo. Novo deve ser o jeito de caminhar. Isso significa dizer que temos todas as ferramentas em nossas mãos, mas precisamos utilizá-las de forma responsável e coerente com os objetivos que pretendemos alcançar. E, não custa nada repetir que, o livro (a leitura) é passaporte, é bilhete de partida para a interação com o mundo. Resta a cada um de nós, educadores, fazer a nossa parte. 


\section{REFERÊNCIAS BIBLIOGRÁFICAS}

ALVES, Rubem. A alegria de ensinar. 8. ed. Campinas: Papirus, 2004.

ANTUNES, Irandé. Língua, texto e ensino: outra escola é possível. São Paulo: Parábola Editorial, 2009.

CARNEIRO, Agostinho Dias. Uma sinopse de uma gramática textual. In: PAULIUKONIS, Maria Aparecida Lino; GAVAZZI, Sigrid. (Orgs.) Da língua ao discurso: reflexões para o ensino. Rio de Janeiro: Lucerna, 2005.

. A interpretação interpretada. Os novos conhecimentos textuais e a presença do texto nos livros didáticos. São Paulo, USP, Faculdade de Filosofia, Letras a Ciências Humanas: 2002. Tese de doutorado em linguística.

CHARAUDEAU, Patrick. Linguagem e discurso: modos de organização. Coord. da equipe de trad. Ângela M. S. Corrêa; Ida Lúcia Machado. São Paulo: Contexto, 2008.

. Análise do discurso: controvérsias e perspectivas. In: MARI, H. et alli. (Orgs.). Fundamentos e dimensões da Análise do Discurso. Belo Horizonte: Carol Borges - Núcleo de Análise do Discurso. Fale - UFMG, 1999, p. 27-43.

. Les conditions de compréhension du sens de discours. In: Anais do I Encontro Franco-Brasileiro de Análise do Discurso. Rio de Janeiro: UFRJ, 1995, p. 9-16.

. Grammaire du sens et de l' expression. Paris: Hachette, 1992.

DELL'ISOLA, Regina Lúcia Péret. Leitura: inferências e contexto sociocultural. Belo Horizonte: Formato Editorial, 2001.

DOLZ, Joaquim; SCHNEUWLY, Bernard e colaboradores. Gêneros orais e escritos na escola. Trad. e org. Roxane Rojo e Glaís Sales Cordeiro. Campinas, SP: Mercado de Letras, 2004.

FERES, Beatriz dos Santos. A escola "faz questão" de leitores autômatos ou autônomos? A atividade de leitura no Ensino Fundamental. Dissertação de Mestrado em Letras. Niterói: UFF, Instituto de Letras, 2003.

FIORIN, José Luís. Teorias do discurso e ensino da leitura e da redação. Gragoatá. nº 1 (2. sem. 1996). Niterói: EDUF, 1996. 
FREIRE, Paulo. Pedagogia da autonomia: saberes necessários à prática educativa. São Paulo: Paz e Terra, 1996.

INAF $-5^{\circ}$ Indicador Nacional de Alfabetismo Funcional: um diagnóstico para a inclusão social pela educação. Avaliação de leitura e escrita. São Paulo: Instituto Paulo Montenegro; Ação Educativa, setembro de 2005. Disponível em: < www.ipm.org.br > Acesso em: maio de 2008.

Indicador de Alfabetismo Funcional. INAF/Brasil - 2007. São Paulo: Instituto Paulo Montenegro; Ação Educativa, s/d. Disponível em: < www.ipm.org.br > Acesso em: maio de 2008.

MARCUSCHI, Luiz Antônio. Produção textual, análise de gêneros e compreensão. São Paulo: Parábola Editorial, 2008.

. Compreensão de texto: algumas reflexões. In: DIONÍSIO, Ângela Paiva; BEZERRA, Maria Auxiliadora (Orgs.) O livro didático de português: múltiplos olhares. Rio de Janeiro: Lucerna, 2001, p. 46-59.

. Exercícios de compreensão ou copiação. In: Em Aberto. Brasília, ano 16, nº 69, jan./mar. 1996.

MARTINS, Maria Helena. O que é leitura. São Paulo: Brasiliense, 1994.

NEVES, Iara Conceição Bitencourt et alli. (Orgs.) Ler e escrever: compromisso de todas as áreas. 8. ed. Porto Alegre: UFRGS, 2007.

QUEIRÓS, Bartolomeu Campos. O livro é passaporte, é bilhete de partida. In: PRADO, Jason; CONDINI, Paulo (Orgs.) A formação do leitor: pontos de vista. Leia Brasil, 1999. (www.leiabrasil.com.br/)

SEFFNER, Fernando. Leitura e escrita na história. In: NEVES, Iara Conceição Bittencourt et alli. (Orgs.) Ler e escrever: compromisso de todas as áreas. 8. ed. Porto Alegre: UFRGS, 2007.

SILVA, Ezequiel T. da. Elementos de pedagogia da leitura. São Paulo: Martins Fontes, 2005a.

. $O$ ato de ler: fundamentos psicológicos para uma nova pedagogia da leitura. 10. ed. São Paulo: Cortez, 2005b.

VIEGAS, Ilana da Silva Rebello. Conteúdos de interpretar - a leitura como passaporte para a interação com o mundo. Tese de doutorado em letras. Niterói, UFF, Instituto de Letras, 2009. 